\title{
SCIENTIFIC REPORTS

\section{OPEN Annihilating Pores in the Desired Layer of a Porous Silicon Bilayer with Different Porosities for Layer Transfer}

Received: 10 December 2018

Accepted: 20 August 2019

Published online: 02 September 2019

\section{C.-C. Chiang \& Benjamin T.-H. Lee}

A silicon layer that is tens of micrometers thick on a handle substrate is desired for applications involving power devices, microelectromechanical systems (MEMS), highly efficient silicon solar cells $(<50 \mu \mathrm{m})$, etc. In general, if the initial silicon layer obtained from the layer transfer process using the etch-stop or ion-cut techniques, which may provide very accurate thickness control, is too thin, then additional epitaxial growth is required to increase the thickness of the silicon layer. However, epitaxial growth under strict predeposition conditions is a time-consuming and expensive process. On the other hand, producing porous silicon via anodization in a hydrofluoric acid solution offers an efficient way to control the dimensions of the generated pores directly on the nano- or macroscale via the current density. When sintering the porous layer via high-temperature argon annealing, the porosity of the porous layer determines whether this porous layer can serve as a device layer or a separation layer. In addition, it is clearly easier to create a transferred layer ten of micrometers thick via anodization than by ion implantation and/or epitaxial deposition.

The layer transfer technique, based on a defined cutting position and wafer-bonding technology ${ }^{1,2}$, can transfer a layer from a crystalline substrate onto a desired substrate. This technique has great flexibility in terms of a sub-microscale thickness- $0.5 \mu \mathrm{m}$, for example-but maintains the crystalline quality and properties of the original substrate, which has proven helpful in the development of some innovative applications such as hybrid integration of IC and MEMS ${ }^{3}$, high-efficiency solar cells ${ }^{4,5}$, and device layer transfer ${ }^{6-8}$.

One of the best examples of the application of the layer transfer technique is in the fabrication of SOI (silicon on insulator) materials. The available manufacturing methods are considerably different ${ }^{1,2,9-11}$ for making different SOI thicknesses for various applications. For example, to fabricate ultrathin SOI materials (silicon thickness $<0.1 \mu \mathrm{m}$ ), ion-cut technology is a quite mature and appropriate technology. For the fabrication of thick SOI materials $(10 \mu \mathrm{m}<$ SOI silicon thickness $<100 \mu \mathrm{m})$, fine grinding and polishing is most frequently used. When the SOI silicon thickness is between $1 \mu \mathrm{m}$ and $10 \mu \mathrm{m}$, the manufacturing is more difficult than for other thicknesses. Typically, the procedure combines ion-cut processing with an epitaxial growth technology for fabrication because such a thickness range is outside the regular scope of polishing-thinning or hydrogen ion-cutting. However, the cost of this type of thick SOI manufacturing may be increased greatly if the layer transfer process involves ion implantation and epitaxial growth.

The reason for developing a layer-transfer process for thin-film solar cells is that a thinner wafer thickness of the silicon solar cells corresponds to a greater reduction in the consumption of the silicon substrate and a greater increase in cell efficiencies ${ }^{12}$. These benefits have prompted many renewable energy research teams to study kerfless techniques ${ }^{13,14}$ for producing silicon layers with thicknesses of tens of micrometers $(<50 \mu \mathrm{m})$ with layer-transfer processing. When manufacturing solar cells, the two processes of ion-cut and epitaxial growth are ideally used as little as possible. Here, we demonstrate a layer-transfer method using only an electrochemical process to produce a porous silicon bilayer or multilayer as both the device layer and the separation layer while omitting the ion implantation and epitaxial growth steps.

Since 1995, the ELTRAN process developed by Sato et al. ${ }^{15}$ has utilized a porous silicon layer as a separation layer to detach a predeposited silicon layer to transfer this layer onto a desired substrate for many applications ${ }^{16-18}$. requests for materials should be addressed to B.T.-H.L. (email: benlee@ncu.edu.tw) 
When applying this process to the manufacture of thin-film solar cells, the silicon layer needs to grow into a layer tens of micrometers thick via the silicon epitaxial growth technique. Based on the concept of interaction between the porous silicon separation layer and silicon epitaxial growth, various extensive methods have been developed to grow the top device layer on the separation layer, such as SONY's sintered porous silicon (SPS) $\operatorname{method}^{19}$, kerfless layer transfer ${ }^{13}$, and quasi-monocrystalline porous silicon (QMPS) ${ }^{20,21}$. In addition, IMAC uses thermal stresses to delaminate the thick silicon layer from a silicon ingot predeposited by a thick metal layer with a large difference in the thermal expansion coefficient (e.g., silver) ${ }^{22,23}$. A multilayer porous silicon structure incorporating recrystallization techniques is used in an alternative manufacturing method.

There are several approaches to fabricating a multilayer porous silicon structure ${ }^{24}$, such as performing anodization with alternating doping concentration layers, anodization with alternating operation temperatures, or anodization with alternating applied current densities. Because the dissolution of silicon preferentially occurs at the pore tips, where the field is concentrated ${ }^{25,26}$, the porosity of the layer formed previously is almost unchanged during subsequent etching. To create such multilayer structures, a variable current density is applied.

This layer transfer method prepares a transferable silicon layer in three main steps. First, it produces a low- to high-porosity porous silicon bilayer by applying variable current densities to change the porosity during anodization processing. We define the thickness of the device layer via time control. The optimum thickness of the top porous silicon layer used in this technique is in the range of 1 to $50 \mu \mathrm{m}$. Second, it applies a high-temperature argon annealing technique ${ }^{27,28}$ to close the pores in the top porous silicon layer, thereby converting it into a defect-free crystalline layer. Finally, it transfers the fused top silicon layer of the device onto the desired substrate using the wafer-bonding technique.

The principle of using varying currents to create different-porosity layers is based on the Lehmann-Gösele model $^{26,29}$. They suggested that in an acidic electrolyte containing fluoride ions, the application of an anodic potential can cause an electrochemical dissolution reaction (i.e., one involving $\mathrm{SiF}_{6}{ }^{2-}$ ) on the surface of the silicon substrate. The surface of the silicon substrate then forms porous silicon and Si-F bonds. The chemical reaction equations are as follows:

$$
\begin{gathered}
\mathrm{Si}+2 \mathrm{HF}+\mathrm{h}^{+} \rightarrow \mathrm{SiF}_{2}+\mathrm{H}_{2}+\mathrm{e}^{-} \\
\mathrm{SiF}_{2}+2 \mathrm{HF} \rightarrow \mathrm{SiF}_{4}+\mathrm{H}_{2} \\
\mathrm{SiF}_{4}+2 \mathrm{HF} \rightarrow \mathrm{SiF}_{6}^{2-}+2 \mathrm{H}^{+}
\end{gathered}
$$

When the applied current varies, changes in the rate of the dissolution reaction change the porosity.

After the porous silicon bilayer forms, argon annealing may be used to convert the top porous silicon layer into a defect-free crystalline layer through reorganizing and annihilating pores. Milenkovic et al.$^{30}$ reported that based on an X-ray diffraction rocking curve, a $950^{\circ} \mathrm{C}$ annealing treatment can shift the peak of as-etched porous silicon to higher diffraction angles, changing a tensile out-of-plane strain into a compressive out-of-plane strain. Because tensile strain usually increases with increasing porosity and mean pore radius, this finding indicates that the pores become much smaller if the strain is changed from tensile to compressive. Moreover, at a higher temperature of $1150^{\circ} \mathrm{C}$, the porous layer may "relax" to greatly reduce the compressive strain. The conversion efficiency of thin-film solar cells fabricated by the shallow emitter formation process ${ }^{31}$ is $12.5 \%$ when using the silicon substrate prepared by this layer-transfer technique. However, the conversion efficiency may be higher if not limited by the performance of the fabricating equipment.

\section{Experiment and Theory}

In Fig. 1, we illustrate the steps of the layer transfer process we developed and make a comparison with other layer-transfer technologies. The sequence of the layer-transfer process based on a porous silicon-based structure is depicted schematically in Fig. 1a. First, the use of an HF-based anodization process forms a porous silicon stack with different porosities on the surface of the silicon specimen by adjusting the current density. The demonstrated porous silicon stack is in a bilayer structure created by a nearly $50 \mu \mathrm{m}$ thick low-porosity device layer and a $10-15 \mu \mathrm{m}$ thick high-porosity separation layer. After anodization, the specimen is blown dry by argon in a quartz tube and then annealed in argon at an ambient temperature of $950-1100^{\circ} \mathrm{C}$, which results in sintering of the porous silicon. Sintering the porous silicon not only seals the pores to form a crystalline layer in the low-porosity layer but also causes the Ostwald ripening process to occur, forming a split plane in the high-porosity layer. Figure $1 \mathrm{~b}$ displays a comparison with other layer-transfer technologies, such as the similar process of first forming porous silicon as a separation layer and epitaxially growing a thick silicon layer as a device layer. The layer-transfer technology integrated with anodization, argon annealing, and wafer bonding has at least two benefits-omitting expensive epitaxial growth processing and recycling the host substrate.

In the study, all of the specimens were cut into squares of $5.0 \times 5.0 \mathrm{~cm}^{2}$ from a prime grade, boron-doped, $1 \sim 10$ $\Omega-\mathrm{cm}(100)$ silicon wafer. The radius of the anodized region was a disk with a radius of $13.6 \mathrm{~mm}(\mathrm{area}=5.81$ $\left.\mathrm{mm}^{2}\right)$. The specimens were cleaned in RCA $\left(\mathrm{NH}_{4} \mathrm{OH}: \mathrm{H}_{2} \mathrm{O}_{2}: \mathrm{H}_{2} \mathrm{O}=1: 1: 5\right)$ and then anodized in a Teflon electrolytic tank filled with hydrofluoride solution ( $\mathrm{HF}$ at $42 \%: \mathrm{C}_{2} \mathrm{H}_{5} \mathrm{OH}$ at $99.5 \%=1: 1$ ).

The use of an applied current (100-300 mA; i.e., current density $\left.=17-52 \mathrm{~mA} / \mathrm{cm}^{2}\right)$ controlled the porosity of the porous layer, and the anodization time (10-60 minutes) determined the thickness of the porous layer. In this study, the silicon specimen was immersed in an HF-based electrolyte solution. Then, an initial anodization step was carried out under the first condition of 100-150 mA, and after 20-50 minutes, anodization was conducted at $300 \mathrm{~mA}$ for 10-20 minutes. The initial applied current was lower than the subsequent applied current to create a low- to high-porosity bilayer structure in the porous layer. 


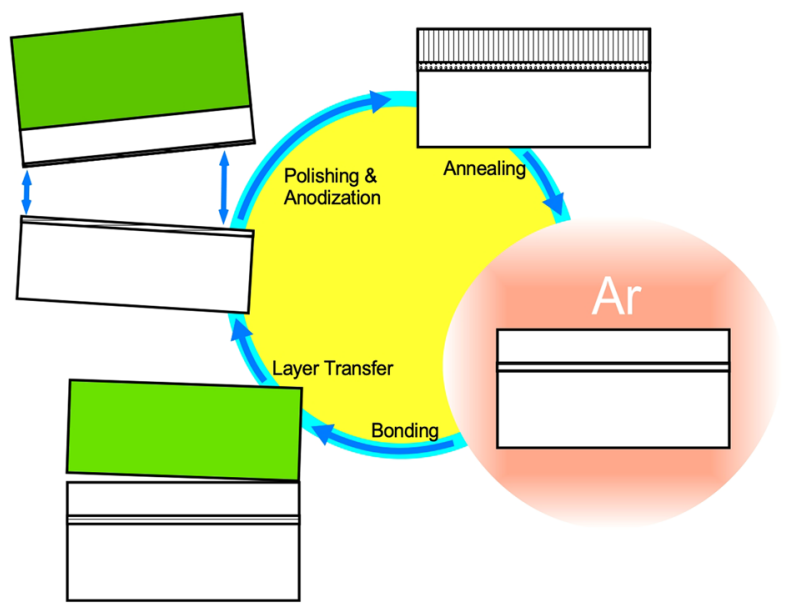

a

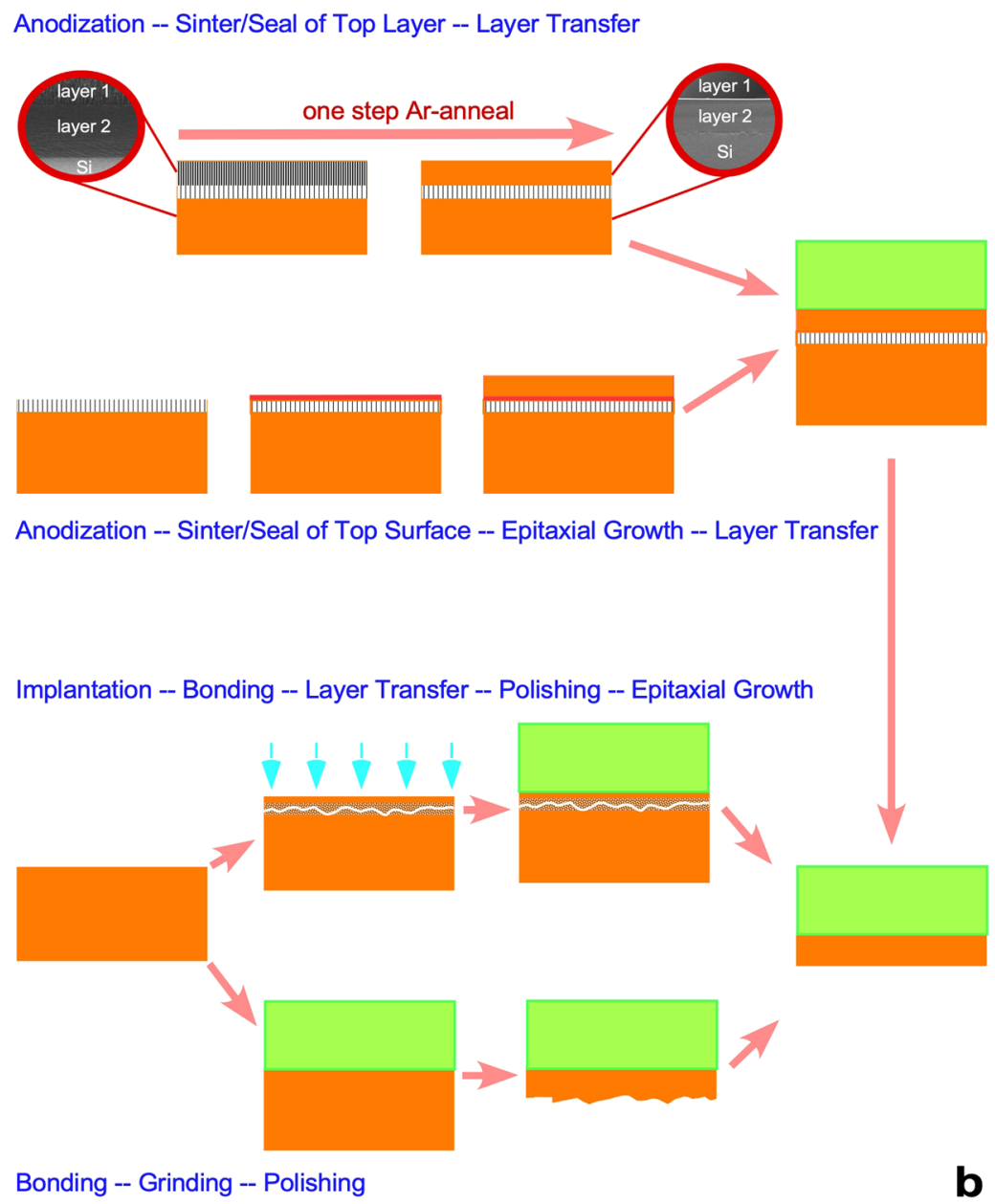

Figure 1. The flowchart for a thick silicon layer transfer technique enabled merely by anodizing the silicon substrate and a comparison with other layer-transfer-based processes. (a) The steps in forming a device layer on a host substrate during layer transfer are (1) forming the first porous silicon layer with a low porosity, (2) forming the second porous silicon layer with a high porosity, (3) annealing the anodized specimen in argon at a high temperature to convert the second porous silicon layer into a device layer, (4) performing wafer bonding to combine the specimen with a handle substrate, and (5) splitting the device layer from the host substrate via the separation layer. The surface of the remaining host substrate may be polished and recycled as a new host substrate. (b) The thick layer-transfer technology in the study (top), with a comparison to other layer transfer techniques (anodization + epitaxial growth (second), ion-cut process + epitaxial growth (third), and grinding/ polishing (last)). The thick layer-transfer technology shown at the top omits the epitaxial growth processing and recovers the host substrate. 

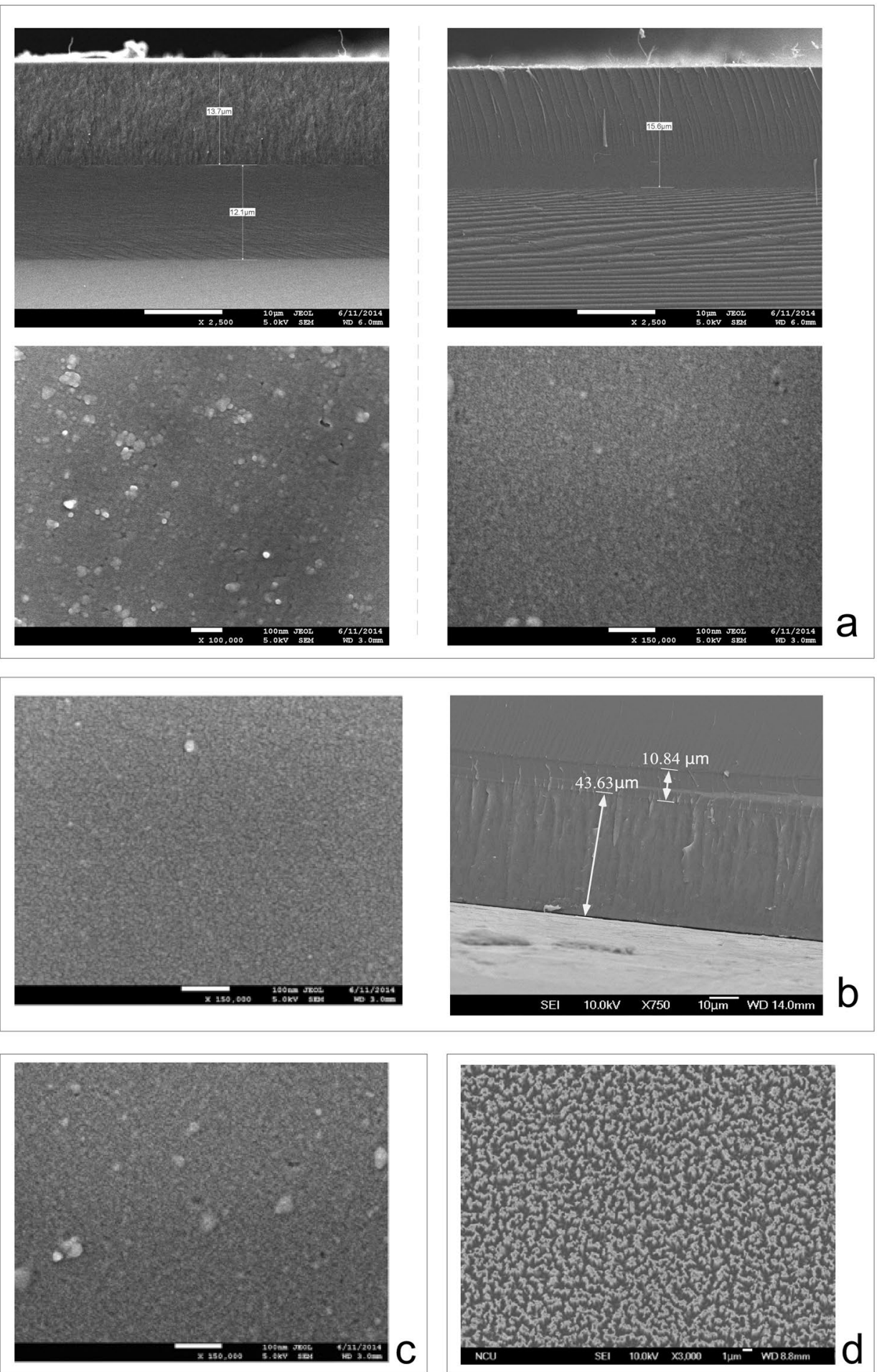

Figure 2. SEM observation of porous silicon bilayers with different porosities obtained using different current densities in an anodization sequence. (a) SEM observation of the side view (upper row, right and left) and top view (lower row, right and left) of the porous silicon bilayer formed by two current densities. SEM images of the side view of the $1-10 \mathrm{ohm}-\mathrm{cm}$, p-type silicon specimens obtained by anodization at $8.6 \mathrm{~mA} / \mathrm{cm}^{2}$ for 10 minutes and then at $25.8 \mathrm{~mA} / \mathrm{cm}^{2}$ for 20 minutes. After anodization, the specimens were (before, left; after, right) annealed in argon at $1000^{\circ} \mathrm{C}$ for one hour. After annealing in argon, the porous column was sintered into a solid layer, which caused the scratched appearance during the cutting portion of the SEM sample preparation. The morphology is different from that in which the porous column exhibited a ruptured powdery trace before annealing, as shown in the figures in the upper row (the right panel and the underlayer in the left panel). (Scale $\mathrm{bar}=10$ microns). (b) The top view (left) and the side view (right) of the bilayer formation of porous silicon using SEM: No pores appeared on the top surface of the upper porous layer. The upper silicon porous layer is $43.63 \mu \mathrm{m}$ thick, and the bottom porous silicon layer is $10.84 \mu \mathrm{m}$ thick after anodizing a $1-10 \mathrm{ohm}$-cm p-type 
silicon specimen at $17.2 \mathrm{~mA} / \mathrm{cm}^{2}$ of current density for 50 minutes and then at $52 \mathrm{~mA} / \mathrm{cm}^{2}$ of current density for 10 minutes. (Scale bar $=100 \mathrm{~nm}$ ). (c) The top view of the porous silicon bilayer obtained using SEM. The silicon porous bilayer was formed by anodizing a $1-10 \mathrm{ohm}-\mathrm{cm}$ p-type silicon specimen at $8.6 \mathrm{~mA} / \mathrm{cm}^{2}$ of current density for 10 minutes and then at $25.8 \mathrm{~mA} / \mathrm{cm}^{2}$ of current density for 20 minutes (scale bar $=100 \mathrm{~nm}$ ). There are some small pores (approximately $10 \mathrm{~nm}$ in diameter) on the top surface of the upper porous layer. (d) The SEM top view of an as-split surface on the transferred layer after annealing. The separation layer was formed from the last porous silicon layer with a porosity of $56.54 \%$. There are many fractured silicon pillars remaining on the $3-5 \mu \mathrm{m}$ surface (scale bar $=1.0$ micron).

The method we used to measure the porosity $(P)$ of the porous silicon layer was based on the weight measurement of the mass of the specimen before (original mass, $\left.m_{0}\right)$ and after $\left(m_{1}\right)$ anodization and the mass $\left(m_{2}\right)$ after merely removing the porous layer. The porosity can be obtained by the equation:

$$
p=\frac{m_{0}-m_{1}}{m_{0}-m_{2}}
$$

Inspection and measurement with TEM, SEM, XRD and polar plots were performed to check the material quality of the transferred layer, and the results are explicated in the associated figure descriptions.

\section{Results and Discussion}

After anodization, the initial $43.6 \mu \mathrm{m}$ porous layer had a porosity of $20-30 \%\left(50\right.$ minutes, $\left.17 \mathrm{~mA} / \mathrm{cm}^{2}\right)$, and the later-forming $22 \mu \mathrm{m}$ porous layer had a doubled porosity of $50-60 \%\left(10\right.$ minutes, $\left.52 \mathrm{~mA} / \mathrm{cm}^{2}\right)$. The last porous silicon layer serves as a separation layer between the device layer formed from the initial porous layer and the silicon substrate. The reduction in the thickness of the separation layer was approximately $30-40 \%$ after annealing, so that the final thickness was close to $14 \mu \mathrm{m}$. The $950-1100^{\circ} \mathrm{C}$ argon annealing process was used to fill the upper porous layer by enabling the in-diffusion of neighboring silicon atoms and promoting the Ostwald ripening of pores in the bottom porous layers. As shown in the scanning electron microscope (SEM) pictures in Fig. 2, the highly porous buried layer yielded large cavities and, thus, a mechanically weak layer, but the low-porosity layer was sealed, resulting in a crystalline device layer. In the appendix, we show that on a silicon wafer anodized under different current densities, different void-ratios are presented. After high-temperature annealing of the anodized specimens in argon, the layer with a lower porosity was sintered to a bulk layer with recrystallization, while the layer with a high porosity exhibited a void-filled status. We choose the best mode to illustrate the layer transfer processing utilizing the sintering characteristics of bilayer porous silicon, as shown in Fig. 2.

In Fig. 2a, the upper silicon porous layer is $13.7 \mu \mathrm{m}$ thick, and the bottom porous silicon layer is $12.1 \mu \mathrm{m}$ thick. They were created by anodizing the silicon specimen at $8.6 \mathrm{~mA} / \mathrm{cm}^{2}$ for 10 minutes and then at $25.8 \mathrm{~mA} / \mathrm{cm}^{2}$ for 20 minutes. The anodized specimens were then annealed in argon at $1000^{\circ} \mathrm{C}$ for one hour. The SEM images show the different surface morphologies caused by SEM sample preparation between the unsintered porous layer (ruptured trace) and the sintered porous layer (scratch track). Adjusting the final current density can modify the porosity of the last porous silicon layer. However, we found several pores on the surface of the top porous silicon layer (device layer), as shown in Fig. 2c. These pores disappeared at the highest and final current density of $52 \mathrm{~mA} /$ $\mathrm{cm}^{2}$, as shown in Fig. $2 \mathrm{~b}$ (left). It is well known that larger currents may more easily pass through the top porous silicon layer without reacting with the pore wall, meaning that the bottom silicon substrate will be anodized to form a new porous layer with a larger porosity ${ }^{24,32}$.

When the anodization time of $17.2 \mathrm{~mA} / \mathrm{cm}^{2}$ was prolonged to 50 minutes, the thickness of the top porous silicon layer after annealing was $43.6 \mu \mathrm{m}$, which is very close to the target thickness of $50 \mu \mathrm{m}$, as shown in Fig. 2 (right). The follow-up anodization time can be fine-tuned via testing to ensure that the thickness of the porous silicon layer after annealing is as close as possible to $50 \mu \mathrm{m}$.

In the oxygen-plasma-activated wafer bonding technique, the Ar-annealed silicon specimen was bonded to a handle silicon substrate covered with an oxide layer by annealing at $200^{\circ} \mathrm{C}$ for 5 hours. As shown in the SEM image in Fig. 2d, which shows the top view of the as-split surface on the transferred device layer, there are many fractured silicon pillars remaining on the surface.

Figure 3 a displays a typical graph of the porosity as a function of the current density for the process of anodizing p-type Si for 15 minutes. The appropriate current density range for forming a low-porosity layer ${ }^{33}$ as the device layer is $5.2-26 \mathrm{~mA} / \mathrm{cm}^{2}$ and the range for forming a high-porosity layer proposed to serve as the separation layer is $34-52 \mathrm{~mA} / \mathrm{cm}^{2}$. The peeling percentage is strongly affected by the porosity of the separation layer, as shown in Fig. 3b. The higher the porosity, the more and larger the pores will be, and the lower the strength of the material will be, resulting in easier delamination.

The argon high temperature annealing ${ }^{34-36}$ in this study has the following functions: (a) sealing and fusing the pores in the device layer and (b) automatically smoothing the sealed surface by driving out the hydrogen atoms via breaking the $\mathrm{Si}-\mathrm{H}$ bonds attached to the surfaces of the pore walls. The passivation of the hydrogen molecule is believed to be the obstacle in eliminating the pores completely during anodization. Argon has a strong effect on splitting off the silicon-hydrogen bonds to promote the recovery of silicon crystallization. A structural model proposed by T. W. Sigmon's research group ${ }^{37}$ for removing the amorphous-crystalline interface suggests that cooperative interfacial bond breaking and rearrangement may promote the regrowth process of the crystalline layer. It has been found that high-temperature argon annealing is able to eliminate crystal-originated particles (COPs) within one hundredth of a micrometer of the surface of a Czochralski (CZ)-grown silicon wafer. Furthermore, in the case of a silicon layer formed by a chemical vapor deposition (CVD) process mixed with argon gas, as disclosed in U.S. patent no. 9,287,137, argon is able to drive out dangling silicon-silicon bonds or silicon-hydrogen 

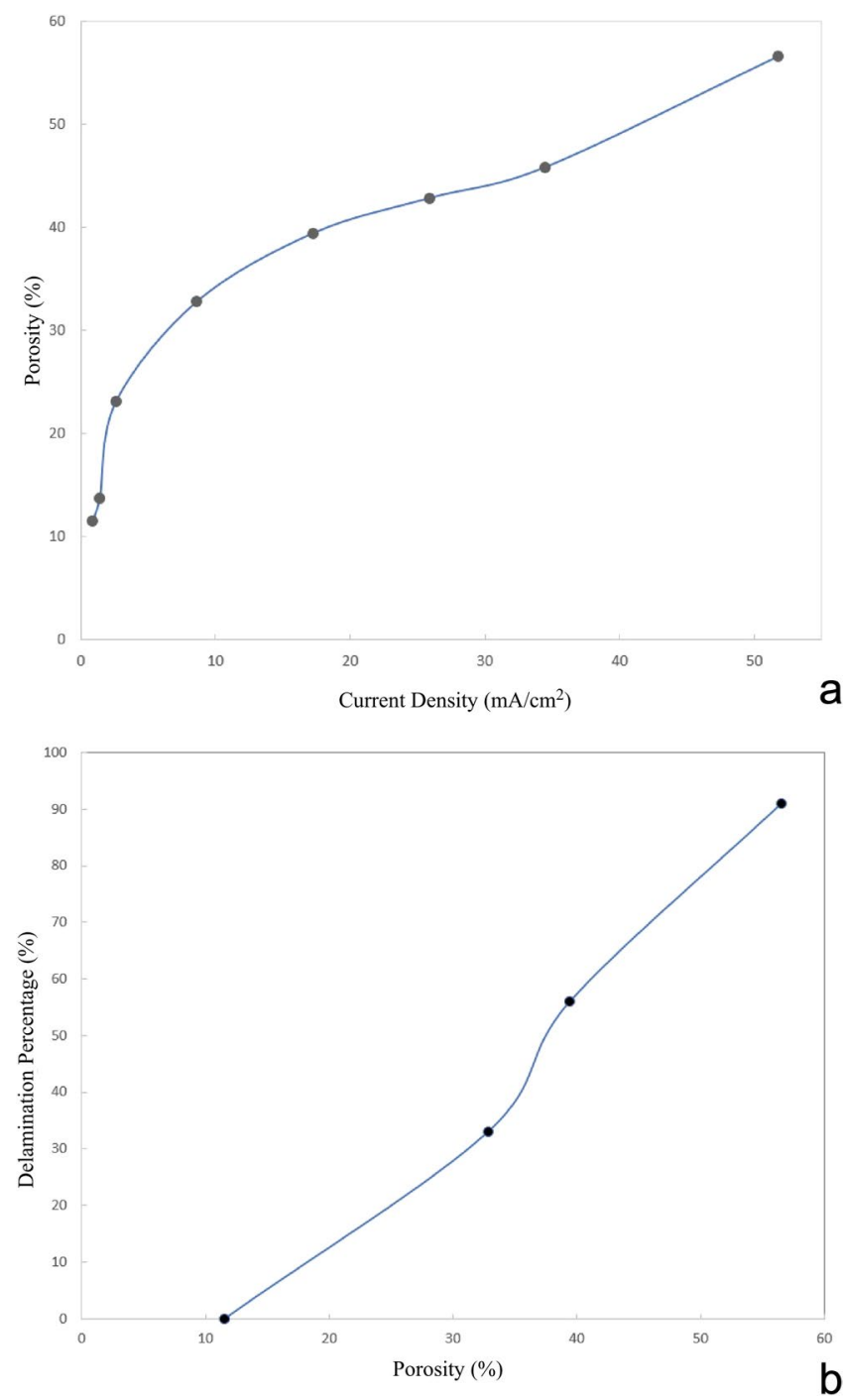

Figure 3. The porosity and growth rate of porous silicon as a function of current density in a p-type silicon substrate anodized in the $\mathrm{HF} / \mathrm{C}_{2} \mathrm{H}_{5} \mathrm{OH}$ electrolyte. (b) Porous silicon layers with various porosities formed after anodizing p-type Si for 15 minutes. The suitable range for producing a porous silicon layer with a low porosity is below $100 \mathrm{~mA}\left(=17 \mathrm{~mA} / \mathrm{cm}^{2}\right)$ and that for producing a porous silicon layer with a high porosity is $200-300 \mathrm{~mA}$ $\left(=34-52 \mathrm{~mA} / \mathrm{cm}^{2}\right)$. (b) Porosity is the important influencing factor for the delamination percentage after bonding the surface of the device layer to a handle substrate.

bonds so that strong silicon-silicon bonds form a hydrogen-free silicon layer. On the other hand, by annealing at a high temperature for a sufficiently long time, the long-range transport of silicon atoms causes silicon atoms in the neighboring regions to fill in the pores in the sponge-like structure, i.e., undergo vacancy diffusion to the surface. The dependence of the growth rate (filling rate) on the substrate orientation should adhere to essentially a geometrical argument in which the regrowth rate-determining step might be equivalent to the time required to grow a row of atoms along the densest (111) planes on the two neighboring crystal surfaces.

As discussed above, by employing the technique of argon annealing, thermally diffused silicon-to-silicon bonding fills in and eliminates the sponge-like structure inside the top, porous silicon layer and then enables a complete recovery of crystallization. In Fig. 4a, the X-ray diffraction (XRD) pattern of the silicon layer shows that the crystalline quality of the porous silicon layer obtained after Ar annealing at $1100^{\circ} \mathrm{C}$ for 3 hours is better than the crystal quality obtained at $1000^{\circ} \mathrm{C}$. The leftmost peaks in the two small figures, a1 and a2, are caused by oxidation. To construct Fig. 4b, a PANalytical X' Pert Pro was used to examine the crystallinity of the silicon layer. In the map of PANalytical $\mathrm{X}^{\prime}$ Pert Pro measurements, the specimens annealed at $1000^{\circ} \mathrm{C}$ had miscellaneous crystal plane orientations, indicating that vacancies might not be eliminated completely, as shown in Figure b1. However, the map shows a clear and uniform crystal plane orientation at $1100^{\circ} \mathrm{C}$ annealing for 3 hours in Figure b2.

Figure $4 \mathrm{c}$ provides direct evidence of the high quality of the device layer after argon annealing at $1100^{\circ} \mathrm{C}$ for 3 hours via transmission electron microscope observation (TEM; 4c). The selected area (electron) diffraction (SAED), as shown in Fig. 4d, reveals a single crystal structure with pores (d1) before annealing and no pores (d2) after annealing. 

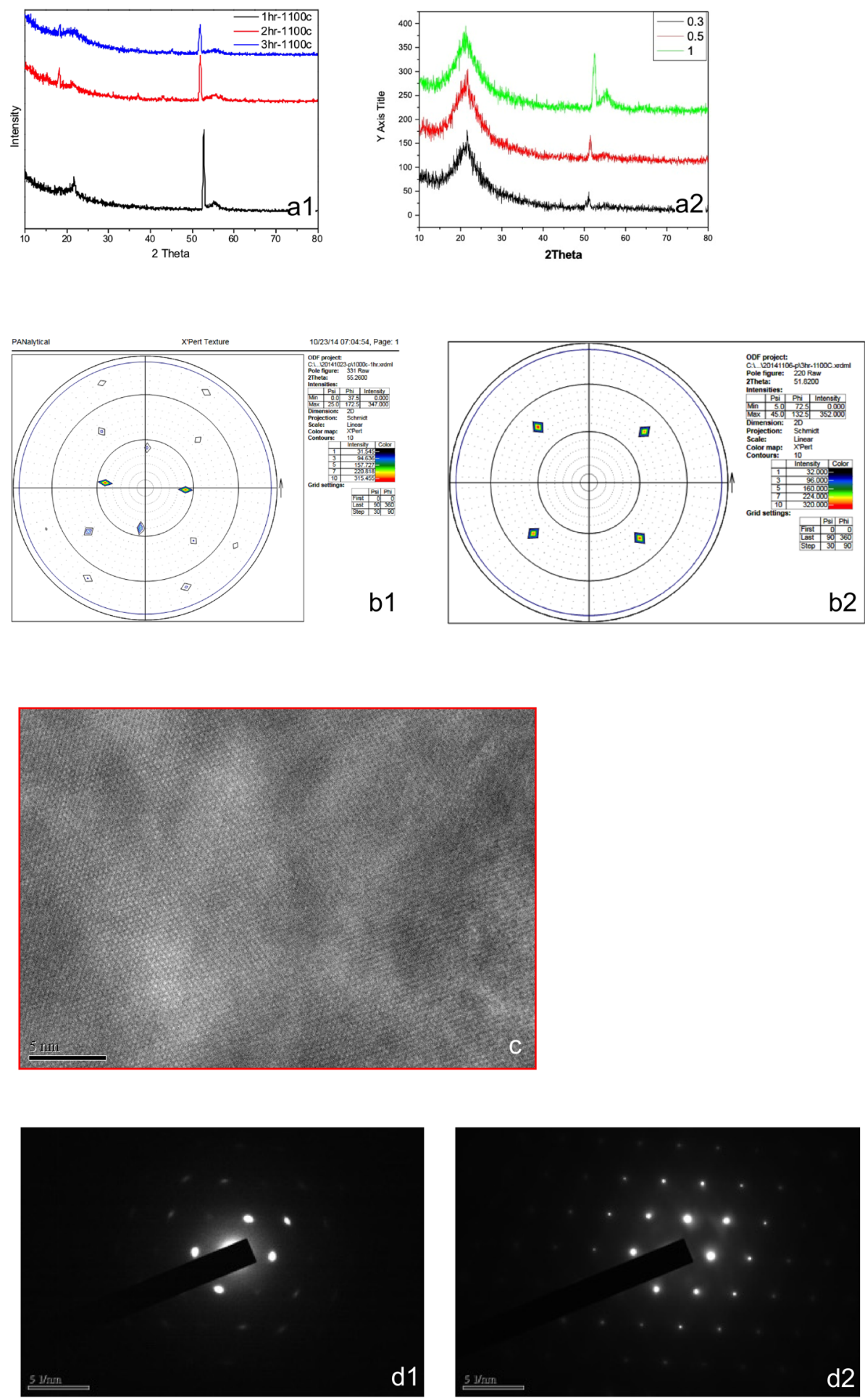

Figure 4. The results of X-ray diffraction (XRD), as measured by the PANalytical $X^{\prime}$ Pert Pro Multi-Purpose Diffractometer, transmission electron microscopy (TEM), and selected area (electron) diffraction (SAED) for evaluating the crystalline quality of the silicon layer annealed at $1000^{\circ} \mathrm{C}$ and $1100^{\circ} \mathrm{C}$, in an argon atmosphere. (a) X-ray diffraction (XRD) pattern of the silicon layer after Ar annealing. The XRD pattern shows that the crystalline quality of the porous silicon layer obtained after Ar annealing at $1100^{\circ} \mathrm{C}$ for 3 hours is better (A1) than the crystal quality obtained under the same conditions at $1000^{\circ} \mathrm{C}$ (A2). The leftmost peak on both graphs is caused by oxidation. (b) PANalytical $\mathrm{X}^{\prime}$ Pert Pro measurements of the crystalline quality of the silicon layer obtained under various annealing conditions exhibited miscellaneous crystal plane orientations, indicating that at $1000^{\circ} \mathrm{C}$, vacancies might not be eliminated completely (B1); however, these vacancies were eliminated completely at $1100^{\circ} \mathrm{C}$ for 3 hours (B2). (c) TEM observation displaying perfect silicon crystals after Ar annealing for 3 hours. (d) Selected-area (electron) diffraction of the (100) silicon device layer before (D1) and after (D2) Ar-annealing at $1100^{\circ} \mathrm{C}$ for 3 hours. 
Summary. In an anodizing process, the porosity and thickness of porous silicon are determined by the magnitude of the current density and the anodization time, respectively. The top porous layer with the lower porosity in the bilayer structure can be filled and reorganized to form a perfect crystalline layer via high-temperature argon annealing. This perfect layer may come about because the high-temperature argon annealing process may decompose some native silicon dioxide if it exists due to exposure to air. Argon annealing not only enhances the out-diffusion of oxygen but also intensifies $\mathrm{Si}-\mathrm{H}$ bond rearrangement to remove hydrogen on the silicon surface and then promotes the in-diffusion of silicon atoms to fill and seal tiny pores. However, in the higher-porosity porous silicon layer, the Oswald ripening process reorganizes many of the pores into large cavities, causing a brittle structure that is suitable for use as a separation layer for layer transferring. Omitting the ion implantation and epitaxial growth processes facilitates the manufacturing of silicon thin-film solar cells, thick SOI wafers, and MEMS components by making this method highly cost-efficient.

\section{References}

1. Tong, Q. Y. \& Gösele, U. Semiconductor Wafer Bonding: Science and Technology. (John Wiley, 1999).

2. Lee, B. T.-H. Nanoscale Layer Transfer by Hydrogen Ion-Cut Processing: A Brief Review Through Recent U.S. Patents. Recent Patents on Nanotechnology 11, 42-49 (2017).

3. Fischer, A. C. et al. Integrating MEMS and ICs. Microsystems \& Nanoengineering 1, 15005 (2015).

4. Cariou, R. et al. III-V-on-silicon solar cells reaching 33\% photoconversion efficiency in two-terminal configuration. Nature Energy 3, 326-333, https://doi.org/10.1038/s41560-018-0125-0 (2018).

5. Geum, D.-M. et al. Ultra-high-throughput Production of III-V/Si Wafer for Electronic and Photonic Applications. Scientific Reports 6, 20610, https://doi.org/10.1038/srep20610, https://www.nature.com/articles/srep20610\#supplementary-information (2016).

6. Stamper, A. K., Farooq, M. G., Fitzsimmons, J. A., Jaffe, M. D. \& Wolf, R. L. Device layer transfer with a preserved handle wafer section (U.S. Patents 9,818,637 B2, 2018).

7. Yonehara, T., Rana, V. V., Seutter, S. M., Moslehi, M. M. \& Tamilmani, S. Systems and methods for laser splitting and device layer transfer (U.S, Patents No. 9,929,054 B2, 2018).

8. Hammond, R. \& Goktepeli, S. Porous semiconductor layer transfer for an integrated circuit structure (U.S. Patent Application No. 20180068886, 2018).

9. Sato, N., Sakaguchi, K., Yamagata, K., Fujiyama, Y. \& Yonehara, T. Epitaxial Growth on Porous Si for a New Bond and Etchback Silicon-on-Insulator. Journal of The Electrochemical Society 142, 3116-3122, https://doi.org/10.1149/1.2048698 (1995).

10. Lee, T.-H., Huang, C.-H., Chang, C.-L. \& Yang, Y.-Y. Producing a transferred layer by implanting ions through a sacrificial layer and an etching stop layer, U.S. Patent No. 8,088,672. United States patent (2012).

11. Auberton-Hervé, A. J. \& Iyer, S. S. INSPEC. EMIS Group. \& Institution of Electrical Engineers. in EMIS processing series no 11 online resource (xxv, 149 p.) ill. (Institution of Electrical Engineers, London, 2002).

12. Reuter, M., Brendle, W., Tobail, O., Werner, J. H. \& Cells, S. $50 \mu \mathrm{m}$ thin solar cells with $17.0 \%$ efficiency. Solar Energy Materials 93, 704-706 (2009)

13. Radhakrishnan, H. S. et al. Kerfless layer-transfer of thin epitaxial silicon foils using novel multiple layer porous silicon stacks with near $100 \%$ detachment yield and large minority carrier diffusion lengths. J Solar Energy Materials and Solar Cells 135, 113-123 (2015).

14. Radhakrishnan, H. S. et al. Improving the quality of epitaxial foils produced using a porous silicon-based layer transfer process for high-efficiency thin-film crystalline silicon solar cells. IEEE Journal of Photovoltaics 4, 70-77 (2014).

15. Sato, N. \& Yonehara, T. Hydrogen annealed silicon-on-insulator. Applied Physics Letters 65, 1924-1926, https://doi. org/10.1063/1.112818 (1994).

16. Yonehara, T. In IEEE SOI-3D-Subthreshold Microelectronics Technology Unified Conference (S3S). 1-3 (IEEE).

17. Gervasoni, M., Machness, A. \& Goorsky, M. Decreased Surface Porosity and Roughness of InP for Epitaxially Grown Thin-Film Devices: A Path to Integration of High Performance Electronics. ECS Transactions 75, 241-245 (2016).

18. Bardet, B., Desplobain, S., Billoué, J., Ventura, L. \& Gautier, G. Integration of low-loss inductors on thin porous silicon membranes. Microelectronic Engineering 194, 96-99 (2018).

19. Brendel, R., Auer, R. \& Artmann, H. Textured monocrystalline thin-film Si cells from the porous silicon (psi). process. Progress in Photovoltaics: Research Applications 9, 217-221 (2001).

20. Majumdar, D., Chatterjee, S., Dhar, M., Dutta, S. \& Saha, H. Light trapping in layer-transferred quasi-monocrystalline porous silicon solar cell. Solar Energy Materials and Solar Cells 77, 51-64 (2003)

21. Banerjee, M., Dutta, S., Gangopadhyay, U., Majumdar, D. \& Saha, H. Modeling and simulation of layer-transferred thin silicon solar cell with quasi monocrystalline porous silicon as active layer. Solid-State Electronics 49, 1282-1291 (2005).

22. Dross, F. et al. Stress-induced large-area lift-off of crystalline Si films. Applied Physics A 89, 149-152 (2007).

23. Bedell, S. W. et al. Layer transfer by controlled spalling. Journal of Physics D: Applied Physics 46, 152002 (2013).

24. Agarwal, V. In Handbook of Porous Silicon 153-162 (Springer, 2014).

25. Lehmann, V. \& Föll, H. Formation mechanism and properties of electrochemically etched trenches in n-type silicon. Journal of the Electrochemical Society 137, 653-659 (1990).

26. Lehmann, V. \& Gösele, U. Porous silicon: Quantum sponge structures grown via a self-adjusting etching process. Advanced Materials 4, 114-116 (1992).

27. Acosta-Alba, P. E., Kononchuk, O., Gourdel, C. \& Claverie, A. Surface self-diffusion of silicon during high temperature annealing. Journal of Applied Physics 115, 134903 (2014).

28. Li, X. et al. Formation speed of atomically flat surface on $\mathrm{Si}(100)$ in ultra-pure argon. Microelectronic Engineering 88, 3133-3139 (2011).

29. Lehmann, V. \& Gösele, U. Porous silicon formation: A quantum wire effect. Applied Physics Letters 58, 856-858 (1991).

30. Milenkovic, N., Drießen, M., Weiss, C. \& Janz, S. Porous silicon reorganization: Influence on the structure, surface roughness and strain. Journal of Crystal Growth 432, 139-145 (2015).

31. Yang, W.-L., Chen, P.-H., Wu, K.-R. \& Wang, L. A novel solar cell shallow emitter formation process by ion-implantation and dopant modulation through surface chemical etching. Journal of Solar Energy Engineering 139, 061001 (2017).

32. Ott, N., Nerding, M., Müller, G., Brendel, R. \& Strunk, H. Evolution of the microstructure during annealing of porous silicon multilayers. Journal of Applied Physics 95, 497-503 (2004).

33. Canham, L. Handbook of porous silicon. 2nd edn, (Springer, 2018).

34. Kakkad, R., Smith, J., Lau, W., Fonash, S. \& Kerns, R. Crystallized Si films by low-temperature rapid thermal annealing of amorphous silicon. Journal of Applied Physics 65, 2069-2072 (1989).

35. Gräf, D. et al. Improvement of Czochralski Silicon Wafers By High-Temperature Annealing. Journal of The Electrochemical Society 142, 3189-3192 (1995).

36. Mozer, A. P. New developments in silicon Czochralski crystal growth and wafer technology. Materials Science Engineering: B 73, 36-41 (2000).

37. Toet, D. et al. Laser crystallization and structural characterization of hydrogenated amorphous silicon thin films. Journal of Applied Physics 85, 7914-7918 (1999) 


\section{Acknowledgements}

The authors wish to thank Prof. Likam Wang (Inst. of Photonics Technologies, National Tsing Hua Univ., Taiwan) for discussion and technical help in fabricating solar cells and Prof. Pi-Chun Juan (Dept. of Materials Engineering, Ming Chi Univ. of Tech., Taiwan) for assistance in the measurement of the material properties of the transferred silicon layer. The publication was supported by the Ministry of Science and Technology, Taiwan, Republic of China (Contract Numbers: MOST 103-3113-E-007 -003, MOST 107-2221-E-008 -006 and MOST 107-2218-E$011-020)$.

\section{Author Contributions}

B.L. designed the study, C.C. conceived and set up the experiments, C.C. performed the experiments and collected the data, B.L. and C.C. analyzed and discussed the experimental results, and B.L. wrote the manuscript.

\section{Additional Information}

Competing Interests: The authors declare no competing interests.

Publisher's note: Springer Nature remains neutral with regard to jurisdictional claims in published maps and institutional affiliations.

(c) (i) Open Access This article is licensed under a Creative Commons Attribution 4.0 International License, which permits use, sharing, adaptation, distribution and reproduction in any medium or format, as long as you give appropriate credit to the original author(s) and the source, provide a link to the Creative Commons license, and indicate if changes were made. The images or other third party material in this article are included in the article's Creative Commons license, unless indicated otherwise in a credit line to the material. If material is not included in the article's Creative Commons license and your intended use is not permitted by statutory regulation or exceeds the permitted use, you will need to obtain permission directly from the copyright holder. To view a copy of this license, visit http://creativecommons.org/licenses/by/4.0/.

(c) The Author(s) 2019 